\title{
The Prediction of Earnings per Share through the Models of Random Walk and Random Walk with Drift: A Case Study of Jordan
}

\author{
Dr. Shukairi Nori Musa, Dr. Issa Ahmad Al-Swiety
}

\begin{abstract}
This research aims to compare the accuracy of the expectation of Earnings per Share (EPS) resulting from two models of expectation which are: Random Walk and Random Walk with Drift (or with deviations). The study has been relying on historical data published by Amman Stock Exchange. The research sample is amounting to thirteen banks for the period between2005 to 2014. This research seeks to measure the external factors flexibility influencing in determining each share profits from the achieved (EPS). The research resulted indicated that the second model is more accurate in predicting the Earnings per Share, and both of the first and the second models were biased towards reducing their expectations, as the signal of average error in the forecast was negative. The research indicated that there are external factors affecting the Earnings per Share of the profit (EPS), factors such as (inflation, interest rate, indicators of shares prices).
\end{abstract}

Keywords: Earnings Per Share (EPS), Random Walk (The First Model), Random Walk with Drift (The Second Model), predicting, Expectation.

\section{INTRODUCTION}

The per share of the profits distributed by companies contributing to its shareholders of the important indicators that drive investors to rush to company shares without the other, and due to the importance of the per share profit, many specialists study and analyze this subject. The per share measure of the realized profits (EPS) Earnings Per Share, one of the important measure for good performance and profitability and their ability to grow, and it took a prominent concern among researchers because the investor usually seeks from its investment to achieve a return higher than the risks facing him as well as the case of the loaner who wants to deal with successful and profitable companies.

\section{MethodologY}

\subsection{Research Problem}

In Amman Stock Exchange, the investor lacks a specific and available to learn about the expectations of the Earnings per Share (EPS) compared with investors in the financial markets in developed countries, where there are a number of available sources including: Financial analysis, Management forecasts and Time series models.

Assuming the external financial analysis in the Amman Stock Exchange to except companies profits, those expectations are not available to the investors in general, and we also find there are no indicators that the managers of the companies listed on the Amman Stock Exchange do not disclose their expectations towards the expected future profits for their companies.

Thus, the remaining source for the Jordanian investors - to identify the number of the expected Earnings per Share to a certain company - is a time models series and in this research two models will be used: Random Walk and Random Walk with Drift.

\subsection{The Importance of the Research}

There are many parties and various sides that rely on their investment decisions on the amount of information available, particularly those involving the different financial information of the companies and their accessories, and so through the study and its analysis, in addition to the total economic indicators of the national economy.

\subsection{Aim of the Research}

The research aims to come up with the most accurate model to predict the Earnings per Share considering that the most accurate model is the expected number of Earnings per Share less error that 
is scaled with the mean square error scale relative to expectation. The research also aims to know the factors affecting the number of the Earnings per Share through a variety of indicators and through several variables.

\subsection{Research Hypothesis}

The First Hypothesis: Is regarded as the first model (random walk model) is more accurate that the second model (random walk with drift) in predicting the number of Earnings per Share in Jordanian banks.

The Second Hypothesis: Is considered that used in the research are biased towards inflating expectations for the number of Earnings per Share in the Jordanian banks.

The Third Hypothesis: There are external influential factors on the profits of the share in the realized profits and have an impact on the value of one share in the realized profits.

\section{LiTERATURE REVIEW}

Many studies have dealt with the issue of forecasting the companies earnings and dividend per share as well as factors affecting the earnings per share achieved from different aspects of them with regards to determining the most accurate prediction model in forecasting operations, including what dealt with the ability of financial ratios to predict the profits and the shares yield .

In (Shebeita,1993) study which was about forecasting earnings of the companies and dividend per share by using financial statements analysis, the researcher used certain financial ratios and the relative change for them where he found that the following ratios are statistically significant for predicting future profits attributed to the total assets of the companies - took in the study, and these ratios are: The relative change in the long-term debt to shareholders equally, Percentage of ownership, The relative change in the proportion of indebtedness and Short-term indebtedness rate. The percentages of significant statistical forecasting a share yield of the companies found by a researcher are as follows: Shareholders turnover and Relative change in long-term debts to shareholder's equity.

The study of (Roland, 1995) where he compared between the accuracy of the companied managers and the expectations resulting from a range of simple mathematical models, so the researcher chooses a sample of 98 site made by the companies executives in order to compare them with the expectations of a group of simple mathematical models used in determining the value of expectation of the absolute value of the average error relative to expectation and was used in determining bias expectation average error in the forecast . This study has found that there is statistically significant difference between the expectation of business managers and the expectations resulting from mathematical mini models. The study also showed superiority of the simple mathematical model that contains any change in terms of accuracy in predicting earnings per share of the other models study.

In a study by (Waltton, 1998) where he applied his study on a sample of 180 US companies where the study included a period of 16 years by using cluster analysis and found of studies said that some of the financial ratios affect the profitability of the company, which are: Change in obligations within two years to total assets, Retained earnings to total assets, The operating profit to net sales, The operating profit to total assets and The average growth in the earning per share over five years .

The study of (Magi, 2002) to know the affect of the level of overall economic activity in the country on the per share portion in the profits, she found that the economic indicators affect the portion per share in the profits by using models of statistical analysis (averages, and deviations) and she found that the economic variables explain the gain of $20 \%$ of the variance in the level of the companies profits.

In a study by (Ganbar and Nebman, 2005) on the informational content of accounting figures and their ability to influence and predict where the study included 391 company and for a time period of 12 years and the researchers found that the following percentages have the power and influence in predicting future profits and these ratios are : The ratio of the change in the inventory of assets, Percentage change in net sales to assets , The change in the distributed profit per share for previous years, The change in capital expenditures to assets and The change in the accounting rate of return.

In a study by (Hessenly, 2004) on the ability of 29 variable of the accountant percentages on influencing the predicting the expectations of cash (Earnings per Share). This study indicated that the following variables have a positive impact on the prediction of the expected cash flows: The inventory 
The Prediction of Earnings per Share through the Models of Random Walk and Random Walk with Drift: A Case Study of Jordan

and how to evaluate it, Working capital to total assets, Proportion of assets to liabilities, The rate of depreciation to its total assets, Debts, Short-term indebtedness, Income resulting from operations, Cash.

\section{The ThEORETICAL FrameWORK OF THE RESEARCH}

\subsection{Administrative Factors Affecting the Earnings per Share}

A set of administrative factors affecting the earnings per share, including:

1. Expansion of the different aspects of the company activities, as the expansion plans always require increasing financial reserve for the company, and this is deducted from the profits.

2. Regulations and commercial laws in the named country, as normally these laws all for a percentage of the statutory reserve that the company must keep.

3. Stalled debts where the more bad debts, then debt provisions will increase and therefore per share earnings will go down.

4. The Board of Directors' recommendations and wishes of the General Authority from the shareholders of the company.

\subsection{External Factors Influencing the Share Profits}

1. Inflation, where inflation is affecting the country under study, plus or minus in the share earnings from the profits.

2. The interest rate, prevailing interest rates in the banks' influence either by increasing or decreasing Earnings per Share from the profits.

3. Price index stocks, as the price index shares on the Amman Stock Exchange affect Earnings per Share from the profits.

\subsection{Time Series Analysis}

The time series are a group of views on a certain phenomenon and specific times and are frequently equal. The time series analysis are intended to know the change that took place on the phenomenon during a certain period where the phenomenon can be compared to the value of each other because they are measured in the same units and in the same way in different dates and in addition to the reasons for and consequences of these changes and find out what it can be a relationship between phenomenon under study and the other phenomenon.

\subsection{The Intention of the Time Series Analysis}

The time series analysis is aimed at knowing the past and determines the financial changes models for the series, and also aims to give an idea about future models and these models are used by the management in planning, forecasting and setting.

\section{Practical Framework of the Research}

\subsection{The Research Community}

The research community comprises all the Jordanian banks listed on the Amman stock Exchange for the financial papers, amounting to sixteen banks, but the research sample has reached thirteen banks after the exception of the banks published under the following conditions:

- The financial year ends on 31/12 each year

- The bank's capital does not includes preferred shares

- The data bank is available to measure the research variables and allowing the research application

- The bank has not been subjected to disorganized events or entered into another bank or retailing the nominal value of the shares during the period of the study (1999-2008)

As for the special variable factor influencing the share profit, the research community consists of two banks, namely: The Housing Bank, and The Jordanian Ahli Bank.

\subsection{Earnings Exceptions Models}

This research will use the two models: the random walk model and the random walk model with drift (or with deviations) and are depending on the annual Earnings per Share

1. $\mathrm{E}[$ Eps $\mathrm{I}, \mathrm{t}]=[$ Eps I, t-1 $]$

2. $\mathrm{E}[$ Epsi, $\mathrm{t}]=[$ Eps I, $\mathrm{t}-1]+1 / 2 \quad[$ Epsi, tj-Eps I, tj-1 $]$

Whereas: 
Eps $=$ the number of Earnings per Share

$\mathrm{E}[\mathrm{Eps}]=$ the number of the expected Earnings per Share

$\mathrm{i}=$ The company

$\mathrm{t}=$ The year in which the expectation took place

$\mathrm{j}=$ The year

- By using the first model (Random Walk), we find that the number of the expected Earnings per Share is expected to be equal to the number of the actual earnings per share (EPS) in the year preceding the year in which the expectation took place.Look at table (1).

- And by using the second model (Random Walk with Drift), the expected number of Earnings per Share is expected to be equal to the actual number of Earnings per Share for the previous year of expectation added to it the difference between the profit figures per share in the years preceding. Look at Table (2).

\subsection{Statistics Measures}

\subsubsection{The Relative Mean Square Error in Prediction (MSPE)}

This measure in one of the common standard for measuring dispersion errors in mathematical expectation, and the expectation relative error is known as the result from dividing the difference from the expected number of Earnings per Share during the period of actual view during the period (1) and the company (i) by using form (M) on the actual number of earnings per share where:

pei, $\mathrm{t}, \mathrm{m}=($ Fitm - Ait $) /$ Ait

wehereas:

Pei, t, m: represents the relative error in the company expectation (i) during the period (t), and the application of model (m).

Fitm: represents the actual earnings per share the company (i) during the period (t) by applying model (m)

Ait: The actual number of earnings per share of the company (i) during the period (t) and between the table No. (7) the relative error in the expectation of all views using the second model.

To extract the relative error in the prediction of the model (M) we apply the following equation:

MSPem $=1 / \mathrm{NT} \sum_{T=1}^{T} \quad \sum_{I=1}^{N} \quad($ Pei,t,m $)$

Whereas:

T: the expectation period $(2005-2014)$ ten years

$\mathrm{N}$ : the number of companies within the study sample $(\mathrm{N}=1$,

5.3.2. The Average Error in Forecasting (AE)

This measure is considered on one of the biased measures and the expectation not biased when the expected value of the error is zero, regarding that the error in the expectation is the difference between the expected view of the profit number per share and the actual view during the period $(\mathrm{T})$ for the company (i) by using the (M) model. And if the average of the errors of the models (M) expectation was calculated during the study period, then the errors with different views will cancel each other and if the result is zero, then that means that the model is accurately expected the profit number per share but if the result was positive, then this means that the model is biased towards inflating its expectation.

In contrast, the model will be biased towards reducing its expectations outcome of the mistake in the model forecasts negative.

You can extract the average error in the prediction of the model $(\mathrm{M})$ by using the following equation:

$\mathrm{AEm}=1 / \mathrm{NT} \sum_{T=1}^{T} \quad \sum_{\mathrm{I}=1}^{\mathrm{N}} \quad($ Fi tm-Ait $)$

\section{ANALYSIS AND DISCUSSION}

The most accurate model to predict the earnings per share (EPS) will be determined, as well as knowing the impact of external factors such as: (inflation, stock price index, interest rate) on the share profits. The researchers will rely on the accuracy of the measured models used expectations on the statistical measure is the "average error in the prediction of the model is equal to zero," also will study 
The Prediction of Earnings per Share through the Models of Random Walk and Random Walk with Drift: A Case Study of Jordan

the effect of influencing factors in the earnings per share using the Spearman correlation coefficient in their relationship analysis.

\subsection{Calculating the Expected Earnings per Share}

The way to extract the number of the Earnings per Share (EPS) represents a direct applicability of the models used in the research. By using the first model, we find that the number of the expected Earnings per Share is expected to be equal to the number of the actual earnings per share (EPS) during the year of expectation .And by using the second model, the expected Earnings per Share (EPS) is expected to be equal to the actual number of Earnings per Share (EPS) for the previous year of the year of expectation adding to it the difference between the profit figures per share, in the three years of the previous year, which is the year of expectation . Table (1) indicates the expected Earnings per Share for the years of study and research sample by using the first model and Table (2) indicates the expected Earnings per Share for the years of study and the research value by using the second model.

\subsection{Error in Forecast}

The prediction of accuracy of the Earnings per Share is determined by identifying the error resulting from the expectation, where the difference between the expected view of the earnings per share and the actual view (the expected error) and the statistical measures for accuracy seek to determine the total error that results from the model expectations the sum of the errors resulting from the model expectations during the forecast period (10 years) and for all the companies within the study sample (13 companies) measured by one of a precision measurement in order to determine the accuracy of each model of the study models. Table (3) shows the results of the medium error in forecasting the first model (Random Walk) to all views, while table (4) shows the expected error arising from the second model (Random Walk with Drift) to the all views.

\subsection{The Relative Mean Square Error in Prediction (MSPE)}

Here it was used the statistical measure to determine the most accurate model as the most relatively accurate model in predicting Earnings per Share will result in the lower average for quarter relative error in the expectation.

The two tables $(1,2)$ show the relative mean square error for the research sample, which reaches (MSPE) according to the first model $(5,503)$ where this figure was extracted by dividing the relative total square error of the value of the research on many views, (65) view but the (MSPE) in accordance with the second model reached $(7,223)$.

Table1. Results of the Relative Mean Square Error in the Prediction of the First Model Distributed by the Companies (13 company)

\begin{tabular}{|l|l|l|l|}
\hline $\begin{array}{l}\text { No. of the } \\
\text { company }\end{array}$ & views & The relative error in the expectation square & $\begin{array}{l}\text { The relative mean square error } \\
\text { in the forecast }\end{array}$ \\
\hline 1 & 5 & 0.710 & 0.014 \\
\hline 2 & 5 & 0.451 & 0.090 \\
\hline 3 & 5 & 61.502 & 12.300 \\
\hline 4 & 5 & 113.073 & 22.615 \\
\hline 5 & 5 & 3.264 & 0.653 \\
\hline 6 & 5 & 1.756 & 0.351 \\
\hline 7 & 5 & 0.628 & 0.054 \\
\hline 8 & 5 & 0.643 & 0.129 \\
\hline 9 & 5 & 0.737 & 0.147 \\
\hline 10 & 5 & 172.373 & 34.475 \\
\hline 11 & 5 & 0.723 & 0.145 \\
\hline 12 & 5 & 0.744 & 0.149 \\
\hline 13 & 5 & 2.115 & 0.423 \\
\hline- & - & 357.720 & 5.503 \\
\hline
\end{tabular}

Table2. The Results of the Relative Mean Square Error in the Prediction of the Second Model Distributed According to the Companies (13 company)

\begin{tabular}{|l|l|l|l|}
\hline $\begin{array}{l}\text { No. of the } \\
\text { company }\end{array}$ & views & The relative error in the expectation square & $\begin{array}{l}\text { The relative mean square error } \\
\text { in the forecast }\end{array}$ \\
\hline 1 & 5 & 0.690 & 0.138 \\
\hline 2 & 5 & 0.860 & 0.172 \\
\hline 3 & 5 & 173.464 & 34.773 \\
\hline 4 & 5 & 247.009 & 49.402 \\
\hline
\end{tabular}


Dr. Shukairi Nori Musa \& Dr. Issa Ahmad Al-Swiety

\begin{tabular}{|l|l|l|l|}
\hline \hline 5 & 5 & 4.112 & 0.822 \\
\hline 6 & 5 & 1.001 & 0.200 \\
\hline 7 & 5 & 0.424 & 0.085 \\
\hline 8 & 5 & 1.643 & 0.329 \\
\hline 9 & 5 & 1.147 & 0.229 \\
\hline 10 & 5 & 30.408 & 6.082 \\
\hline 11 & 5 & 1.454 & 0.291 \\
\hline 12 & 5 & 0.572 & 0.114 \\
\hline 13 & 5 & 6.307 & 1.261 \\
\hline- & - & 469.491 & 7.223 \\
\hline
\end{tabular}

\subsection{Results were Classified to their Forecast Bias}

The two researchers, through accounting the average error in forecasting to the research model to determine the direction of the expectations of these two models by taking into account the error signal in the forecast when calculating the average error in the prediction of the model, because the impartial expectation which will be equal with the actual view so that the expected value of the error in the forecast will be equal to zero, and that the expected error is calculated by subtracting the actual view from the expected view, then the result that carries positive signal means that the expected Earnings per Share is greater than the actual Earnings per Share and therefore the model is regarded as biased towards inflating its expectations.

By contrast, the model that the results of its total observations were errors in its expectations of a medium error carries the signal negative and is biased toward reducing its expectations for the Earnings per Share, and the results show (the medium error expectation) for the study model in the tables $(3,4)$ where it is noted that the signal of medium error expectation of the two models is negative, which indicates that these two models reduce their expectations - on the medium - to the number of Earnings per Share.

Table3. The Results of the Medium Error in Forecasting the First Model Distributed According to the Companies, (13 company)

\begin{tabular}{|l|l|l|l|}
\hline Company no & views & Total error prediction & The medium error in forecasting \\
\hline 1 & 5 & $-9,750$ & $-1,914$ \\
\hline 2 & 5 & 0,190 & 0,038 \\
\hline 3 & 5 & 0,072 & 0,014 \\
\hline 4 & 5 & 0,317 & $-0,063$ \\
\hline 5 & 5 & 0,033 & 0,007 \\
\hline 6 & 5 & 0,123 & 0,025 \\
\hline 7 & 5 & $-0,128$ & $-0,026$ \\
\hline 8 & 5 & 0,051 & 0,010 \\
\hline 9 & 5 & 0,023 & 0,005 \\
\hline 10 & 5 & 0,130 & 0,026 \\
\hline 11 & 5 & 0,094 & 0,019 \\
\hline 12 & 5 & 0,190 & 0,038 \\
\hline 13 & 5 & $-9,147$ & 0,008 \\
\hline- & - & $-9,147$ & $-0,141$ \\
\hline
\end{tabular}

Table4. The Results of the Medium Error in the Prediction of the Second Model Distributed According to the Companies, (13 company)

\begin{tabular}{|l|l|l|l|}
\hline Company no & views & Total error prediction & The average error in forecasting \\
\hline 1 & 5 & $-18,446$ & $-3,689$ \\
\hline 2 & 5 & 0,379 & 0,076 \\
\hline 3 & 5 & 0,299 & 0,060 \\
\hline 4 & 5 & $-0,786$ & 0,157 \\
\hline 5 & 5 & 0,278 & 0,056 \\
\hline 6 & 5 & 0,236 & 0,047 \\
\hline 7 & 5 & $-0,091$ & $-0,018$ \\
\hline 8 & 5 & $-0,055$ & $-0,011$ \\
\hline 9 & 5 & $-0,062$ & $-0,012$ \\
\hline 10 & 5 & 0,049 & 0,010 \\
\hline 11 & 5 & 0,034 & 0,007 \\
\hline 12 & 5 & 0,534 & 0,107 \\
\hline 13 & 5 & 0,030 & 0,006 \\
\hline- & - & $-17,602$ & $-0,271$ \\
\hline
\end{tabular}


The Prediction of Earnings per Share through the Models of Random Walk and Random Walk with Drift: A Case Study of Jordan

\subsection{Factors Affecting the Per Share Profits}

There are a number of factors affecting the earnings per share and these factors are (inflation, interest rate, and index of stock prices in the Amman stock market) during the time period (2005-2014) (Note :Table 5), where the relationship will be studied between the earnings per share and these factors. The two researches conducted some of the statistical analyzes using the descriptive statistical analysis (SPSS) for the financial statements in question, and the results of the researcher variables were as follows :

- The medium arithmetic of the inflation during the years in question (7.9\%)

- The medium arithmetic of the interest rates during the years in question (6.2\%)

- The medium arithmetic of the stock prices indicators during the years in question (152.0\%).

Table5. Variables of Study

\begin{tabular}{|l|l|l|l|}
\hline The year & inflation & Interest rates & Stock price index \\
\hline 2005 & $28.6 \%$ & $6.2 \%$ & $133.7 \%$ \\
\hline 2006 & $16.2 \%$ & $6.4 \%$ & $155.6 \%$ \\
\hline 2007 & $8.2 \%$ & $6 \%$ & $146.7 \%$ \\
\hline 2008 & $4 \%$ & $5.3 \%$ & $129.9 \%$ \\
\hline 2009 & $3.3 \%$ & $5.2 \%$ & $158.5 \%$ \\
\hline 2010 & $3.5 \%$ & $5.7 \%$ & $143.6 \%$ \\
\hline 2011 & $2.4 \%$ & $6.1 \%$ & $159.2 \%$ \\
\hline 2012 & $6.5 \%$ & $6.9 \%$ & $153.5 \%$ \\
\hline 2013 & $3 \%$ & $7.4 \%$ & $169.2 \%$ \\
\hline 2014 & $3.2 \%$ & $6.8 \%$ & $170.1 \%$ \\
\hline SMA & $7.9 \%$ & $6.3 \%$ & $152 . \%$ \\
\hline
\end{tabular}

The required data for each of the Housing Bank and the Jordan Ahli Bank in terms of the per share profits as the per share profits during the years of the study were as in the table (6)

Table6. Earnings per Share (Jordanian Dinars)

\begin{tabular}{|l|l|l|}
\hline The year & Jordan Ahli Bank & The Housing Bank \\
\hline 2005 & 0.17 & 0.28 \\
\hline 2006 & 0.10 & 0.27 \\
\hline 2007 & 0.10 & 0.34 \\
\hline 2008 & 0.78 & 0.49 \\
\hline 2009 & 0.46 & 0.55 \\
\hline 2010 & 0.32 & 0.41 \\
\hline 2011 & 0.45 & 0.51 \\
\hline 2012 & 0.50 & 0.52 \\
\hline 2013 & 0.41 & 0.62 \\
\hline 2014 & 0.52 & 0.86 \\
\hline SMA & 0.381 & 0.467 \\
\hline
\end{tabular}

\subsection{Correlation Coefficient between Earnings Per Share and Variables}

Table (7) indicates the correlation coefficient and the degree of error for both of The Ahli Bank and The Housing Bank.

Table7. The Correlation Coefficient and the Degree of Error

\begin{tabular}{|l|l|l|}
\hline The correlation coefficient & The Ahli Bank & The Housing Bank \\
\hline Correlation coefficient & $-0,607$ & $-0,737$ \\
\hline Interest rate & 0,701 & 0,321 \\
\hline Stock price index & 0,090 & 0,675 \\
\hline Inflation & 0,060 & 0,015 \\
\hline Interest rate & 0,042 & 0,365 \\
\hline Stock price index & 0,988 & 0,032 \\
\hline
\end{tabular}

\section{- Study of the Relations}

To find out the correlation between the earnings per share and the previous variables through the correlation coefficient, we find that:

1. The correlation coefficient between the Earnings per Share in the Housing Bank and inflation. After conducting the test, we find the correlation coefficient between them was $(-0,737)$ and has 
statistic means, reaching 0,015 which is lower than the level of significant 0.05 , which means that whenever the inflation increases, earnings per share decreases by 0,737 .

2. According the correlation coefficient between the Earnings per Share of the National Bank and inflation, we find from the test that the correlation coefficient between them was $(-0,607)$ but the level of statistical connotation of this test was weak it amounted to (0.06), which is greater than the significant level of 0.05 and thus, despite the existence of an inverse relationship between these two variables, but the relationship between them is lacking to indicate the statistical explanation.

3. According the correlation coefficient between the Earnings per Share of the Housing Bank and the interest rate, we find from the test that the correlation coefficient was $(0,321)$, a relationship that is positive but weak and this weakness confirms the value of statistical significance which reached $(0,365)$ which is greater than the significance level of 0,05 , which means that the relationship does not show statistically .

4. According the correlation coefficient between the Earnings per Share to the National Bank and the interest rate, we find from the test that the correlation coefficient was $(0,701)$, which is a positive relationship that increase one share profits as the interest rates increase and reach the level of significance reached $(0,042)$ which is less that the significance level of 0,05 .

5. According the correlation coefficient between the Earnings per Share for the Housing Bank and the stock market index, we find from the test that the correlation coefficient was $(0,675)$, a direct and positive relationship which means that when the stock price index increases, then the per share earnings for the Housing Bank increase, especially as the level of statistical implication for this relationship is acceptable, reaching $(0,032)$ and is less that $(0,05)$.

6. According the correlation coefficient between Earnings per Share of the Ahli Bank and the stock market index, we find from the test that the correlation coefficient was very weak, reaching $(0,009)$ and enhancing the level of the statistical indication which amounted to $(0,988)$ which is bigger than the indication level by $(0,05)$, and thus the relationship does not indicate statistically.

\section{CONCLUSIONS AND RECOMMENDATIONS}

\subsection{Conclusions}

- In a comparison between the results of the average square of the relative error in the expectation for the research two models, we find that the lowest average relative error in the forecast resulted from expectation of the first model $(5,503)$, and therefore, the second model is more accurately in predicting the earnings figure where the average relative error in the forecast reached $(7,223)$.

- The research also came out of with results indicate that there are external factors (such as inflation, interest rate, stock price index) that affect the Earnings per Share in addition to internal factors (accounting data).

- The research also indicated that the used two models are biased toward reducing their expectations as the average signal error in the prediction was negative.

- Accordingly, we reject the first hypothesis, which means that the second model is more accurate in predicting the number of Earnings per Share.

- The second hypothesis was also rejected, which states that the two models are biased towards inflating their expectations for the earnings per share while it has been proven that the opposite is the truth in the sense that the two models are biased toward reducing their expectations for the number of Earnings per Share.

- The third hypothesis was accepted considering that there are external factors affecting the earnings per share and some of these factors are (inflation, interest rate, stock price index).

\subsection{Recommendations}

- The number of earnings per share (EPS) is regarded as the most important financial indicators, especially for the investors, so the researcher recommends using this figure and reveals it in the financial statements published for the banks and financial companies compared with the figure of the previous financial year.

- The researchers also recommend the banks and the financial companies managers, the need to try to expect the earnings per share and disclose these expectation process because it is useful for several quarters, whether privately or government so that they can assess the situation of the company properly and know its financial position accurately. 
- The researchers recommend further applicable studies to determine the time series results of the banks and the financial companies' profits in order to anticipate the future profits and to determine the appropriate expectations models for such companies.

- The need to study the factors affecting the per share profits, whether these factors are internal or external, because these factors play a greater role in the value of the per share profits, so that there is not a manipulation of the administration in the profit per share for the purpose of misleading shareholders by increasing Earnings per Share, and let people to come and buy shares and so the share price will increase, which is actually the opposite and therefore the knowledge of these factors will show the expected return accurately.

\section{REFERENCES}

[1] Shebeita, Maaz, 1993: forecasting corporate earnings and dividend per -share by using the financial analysis of the lists, M.A certificate unpublished, the University of Jordan.

[2] Roland, E, loris, 1995: simple math models journal of accounting and business vol 1,

[3] Wallton, G.F Randolph, 1998: Th information content of dividends, journal of accounting and business, vol 24.

[4] Magi, Mampton, 2002: Dilution of Earning per share with number of shares outstanding, International Financial corporation Washington 6/25.

[5] Ganbar, G. John and Nebman, F.E, 2005: corporate Financing and Investment, Decisions when Firms have Information that Investor do not have, journal of financial economics, vol 18.

[6] Messenly M. Frank, 2004: Financing policies and the Market For Control, journal of Financial economics, vol 22

[7] Sobh, Mahmoud, 2002: The financial and economic analysis of the financial markets, the Arab Renaissance Publishing House, Egypt.

[8] Hindi, Munir, 2003: the securities and the capital markets Al-Ma'aref facility, Alexandria, Egypt.

[9] Al- Hinawi, Mohammed Saleh Al-abid, Jalal Ibrahim 2002: the Financial Management: An Introduction value and the decision-making, The University House Alexandria, Egypt.

[10] Al-Zubaidi, Hamza Mahmoud, 2004, the advanced financial management, Al Warraq for Publishing and Distribution, Amman, Jordan

[11] Al-Otoum, Shafiq, 2000 , Introduction to the statistical methods, Al-Taj Press-Jordan

\section{AUTHORS' BIOGRAPHY}

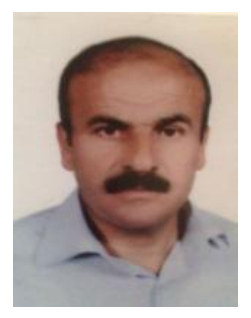

He was born in 1966 -Nablus -Palestine. He has PHD of Finance / Aleppo University, Syria - 2007. He is working now as Assistant Professor in the Finance Department at Zarqa University, Jordan from 2014-2017. He was working as Assistant Professor in the Finance Department at Isra University, Jordan from 20072014. He prepared many articles and books in specialized topics in finance.

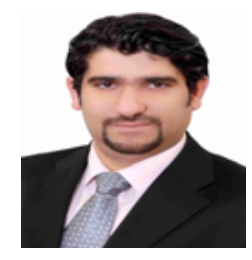

He was born in 1977 -Amman -Jordan. He has PHD of Banking and Financial Sciences /University of Banking and Financial Sciences - Amman, Jordan - 2011.He is working now as Assistant Professor in the Finance Department at Zarqa University, Jordan. He was a relationship manager /SMES DEPARTMENT at Bank of Jordan since 2008 to 2012. He was a relationship manager SMES DEPARTMENT at Cairo Amman Bank since 2004 to 2008. 